\title{
Video Gaming for Blind Learners School Integration in Science Classes
}

\author{
Jaime Sánchez and Mauricio Sáenz \\ Department of Computer Science, Center for Advanced Research in Education (CARE) \\ University of Chile \\ \{jsanchez, msaenz\} @dcc.uchile.cl
}

\begin{abstract}
In this study we evaluate how the use of audio-based technology can facilitate school integration of blind learners through the interaction with a science videogame. This experience consisted of designing and implementing The Natomy's Journey Game to be played by blind and sighted middle school students. The use of the videogame and its impact on the integration of blind learners into mainstream schools was also evaluated, through the participation of both teachers and learners. In the end, the goal was for blind learners to be able to interact and become socially integrated through active science video gaming and the application of specific science content. The results of this study provide initial data and evidence that the use of video games such as The Natomy's Journey Game can improve the process for the school integration of learners with visual disabilities.
\end{abstract}

Keywords: Visual disability, sound interface, school integration, science learning.

\section{Introduction}

The use and integration of ICTs into education has been the focus of discussion for many researchers and developers [2,6]. The use of this kind of technology in education, and in particular for complex content such as science, make its integration for use by the visually disabled through educational activities especially complicated. This is mainly due to the kind of resources required and these students' lack of one of the most important senses for the process of observing natural phenomenon: vision $[9,14]$. Children with visual disability have more problems accessing information, learning and putting basic operations into practice, and solving problems than their sighted peers $[23,13]$. However, the use of technology that is correctly adapted for this kind of disablement can lead to an efficient solution.

As such, we might ask: In what way can we create a context in which sighted and blind students could work collaboratively for effective science learning? In general, in several countries there are special schools for children with visual disabilities that work only with legally blind students as a segregated population. In these cases, there are usually scarce resources, which impede working in the same conditions as their peers in school integrated classes (mainstreaming). 
Several studies have shown that audio interfaces can be used to foment learning and cognition in blind children [22,24,33]. The use of these audio-based applications stimulates the utilization of general cognitive processes, such as tempo-spatial orientation, abstract memory and haptic perception [22,24,27].

In recent years, video games have become a part of the daily life of children and school-aged youth $[15,17]$. With the progress of ICTs, video games have become a powerful force representing a part of the daily activities, concerns and interests of children and youth. In our country, $50 \%$ of students use the Internet to play games $[1,32]$. In the USA, young people between 8 and 18 years old play an average of 49 minutes of video games daily, almost the same amount of time dedicated to doing homework (50 minutes) and reading (43 minutes) [18].

In this way, computer-based video games represent an alternative that has penetrated distinct areas of education, mainly in their use in the classroom [12,30]. Such data demonstrates the potential importance of video games in education as a structure for the development of different cognitive abilities, such as problem solving, analysis, communication, collaboration and information management [29,31].

In taking into account the high degree of learners' motivation and interest in video games, the potential of these games to develop abilities and the need to integrate their use into the formal education of both blind and sighted users, we designed and developed a video game called The Natomy's Journey Game, for interactive collaboration between sighted and blind students. We also evaluated the usability of The Natomy's Journey Game, as well as its impact on the process of school integration between blind students and their sighted peers.

\section{Related Work}

In the last few years several software applications [20,22,24] have been developed involving blind users as the main participants, in order to assist them in their learning with interactive technology, focusing mainly on haptic interfaces [27] and desktop applications [22,24]. Also, there are several studies that show the importance of using video games for education [12,29,31]. Some important cognitive aspects that can be developed through the use of video games are the development of competition and concentration skills, mobility skills, language and mathematical skills, visual skills and problem-solving skills $[3,4,25]$.

However, there is consensus in the literature that problem solving is the most important one of all, in that it provides students with tools that can be used not only in a school context, but in social and work contexts as well.

Polya [16] described the process for problem solving in four fundamental steps that consist of understanding the problem, devising a plan, carrying out the plan and examining the solution obtained. If this does not solve the problem, a new plan has to be devised.

The current literature includes several studies related to virtual environments and problem solving for the blind. In [5], an aid system is proposed for the mobility of a 
blind user through virtual reality mechanisms. In [26] the authors developed virtual reality tools so blind users could explore information constructively. In another study, a game with 3D navigation, Terraformers, was developed for stimulating development and solving tasks in an entertaining way [33]. Recently, some software programs for problem solving through interaction with virtual environments designed for users with visual disabilities have been developed [22,24]. These programs use labyrinths represented in different ways through spatial and stereo audio [34,35]. Access Invaders [36] is a video game that allows for online playing between blind users to solve a shared goal.

School integration is a very important subject nowadays. There are several studies about the present state of integration in the classroom as shown in $[10,11,28]$. On the other hand, several studies on the way that technology can aid in the school integration of users with different kinds of disabilities in the classroom have been developed [7,8]. In another example, in [19, p.57] it was concluded that, "With the large number of mildly disabled students in our schools, it is very important that teachers make every effort to educate their students as best as possible. Evidence has shown that technology is one of the best ways to implement this successfully. Using a variety of software and technology tools this process is becoming easier every day. Teachers must also make sure that they are educated in how to use these tools to better instruct their students' learning. As advancements in the field of technology continue to be made, more and more opportunities for this level of learning will be available to students and, as evidence has shown; more students will have better opportunities to receive the best education possible."

In this study, our proposal is The Natomy's Journey Game, a sound-based game that uses mobile technology so that blind and sighted children can interact, become socially integrated and learn science. In the following we present the main characteristics of the software, as well as an evaluation of its use by blind users and its impact on the process of school integration with their sighted peers.

\section{The Video Game}

\subsection{Video Game Description}

The Natomy's Journey Game represents four systems of the human body in which the student adopts a character with which he/she can interact with other characters in the game or in his/her work group, and thus complete the collaborative tasks necessary to achieve a main goal. These four systems are: the digestive system, the respiratory system, the cardiovascular system and the nervous system. The main problem to solve is to heal certain sicknesses by using the clues that are provided to the students through their interaction and investigation throughout the video game.

The video game was made to be used by workgroups of four students working simultaneously in a computer lab (with a maximum of 12 groups working at the same time). 
The interaction with the legally blind students is based mainly on the use of the keyboard and feedback provided on their actions through a spatial sound system (4 or more speakers distributed in the end-user's surroundings) (see Figure 3).

The game can be played in an individual or a group mode. The user must interact with the characters and objects in the video game that provide clues and symptoms in order to solve the problem at hand. To these ends, the progress of each student depends on the progress of the rest of his/her team, thus creating a variety of interactions between the members of the group.

The game consists of two sicknesses to be discovered (Cholera and Rubella). As the player interacts with the characters, they provide information on the sickness and, at the same time, on the different organs and specific functions of the human body necessary to make decisions. The students must get to a place in the human body called the Center of Operations, where they enter an area of mini-video games that they must successfully complete in order to pass to the next level and to beat the game. Each system of the human body consists of 12 scenes that make up the totality of the virtual world with which the users must interact.

\subsection{The Video Game Metaphor}

The video game metaphor consists of a journey to within a sick human body. This journey is taken by a group of four friends who must go to the city of Natomy, where a crazy genius (Uncle Isaiah) provides them with a pill that they must take in order to shrink in size, to be able to enter the human body.

\subsection{Video Game Architecture}

This game was developed for a PC platform in Macromedia Director using Lingo language. The following system requirements are needed to run the game: $1 \mathrm{GHz}$ processor or higher, Microsoft Windows XP SP2, 256 MB RAM, 32 MB DirectX 8 compatible video and sound card, 4 speakers or headphones for audio, and keyboard.

The software architecture upon which The Natomy's Journey Game is based has two main components: 1. Video game engine, responsible for controlling all the players' interactions, the logical relations and the dependencies between the different systems, 2. Interfaces module, responsible for receiving the users' actions through the keyboard and, at the same time, producing the necessary feedback through graphic objects and audio.

Each of the participating users interacts with the interfaces available in the video game. The users with visual disabilities (legally blind) mostly used the audio interfaces, which orients them and provides updated information on the state of the video game. On the other hand, the sighted users use both interfaces (audio and visual) to receive all the necessary information to be able to play the game correctly.

The information received through the interfaces is processed as input into the game's engine, which evaluates and processes the different logical interactions between all the software's components and the dependencies of these components. Afterwards, it takes the new information produced by the users' interaction, which is then sent to the interfaces to be provided to the users (see Figure 1). 


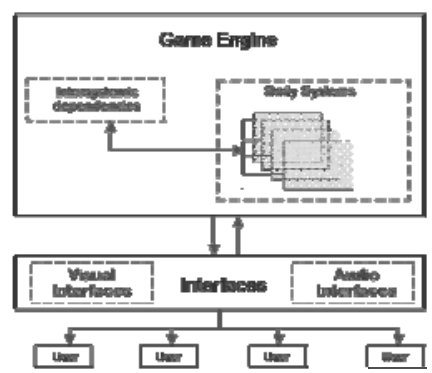

Fig. 1. Architecture of The Natomy's Journey Game

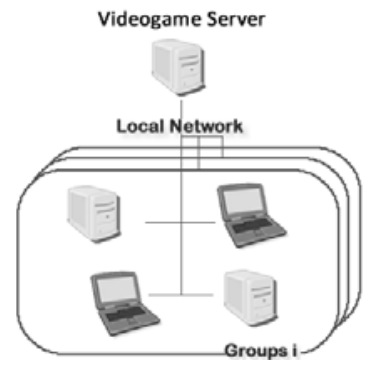

Fig. 2. Networking Architecture of The Natomy's Journey Game

\subsection{Networking Architecture}

The video game's multi-user interaction is carried out through architecture designed over a local network, in which both desktop computers and wireless mobile computers connected through WIFI can be used (see Figure 2).

\subsection{Interfaces}

Audio Interfaces. The audio interface developed for The Natomy's Journey Game consists of a combination of stereo and spatial sound. The stereo sound is utilized mostly for the voices in the game used for the instructions, the different menus, dialogues and some objects in the different scenes. The spatial sound is used mostly to identify the objects in the spatial environment (see Figure 3). This last system was designed so that the students with visual disabilities could orient themselves and recognize the position of the objects, doors and characters in the scene. This corresponds to certain audio elements that are constantly reproduced during the game, such as the entry, exit and doors to the systems of the human body, as well as other elements that are reproduced on-demand, such as the position of objects and characters.

To create a spatial immersion of the user into the virtual environment, the speaker system must be located properly. The front left and front right speakers must be placed in an angle of 45 or 60 degrees. In addition, the 3 frontal speakers must be placed at the same level. The rear speakers must be located behind the user and a little above his ears (see Figure 3). Depending upon how the sound was used, different levels of user immersion were attained. The use of the spatial sound attained the highest level of user's immersion allowing for a high fidelity representation of the audio in a real environment which points out to the user the position of objects and their location within the environment.

Audio interfaces were implemented using MS Directx, in particular the dxSound for Lingo library. This allowed for producing and controlling dynamically the spatial sound of the video game. 


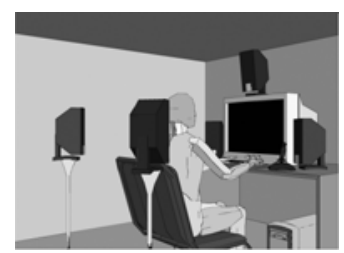

Fig. 3. Scenario for the use of the spatial sound

Visual Interfaces. The visual interfaces developed for the video game The Natomy's Journey Game correspond to caricaturized abstractions of the systems and organs of the human body as well as objects in the game.

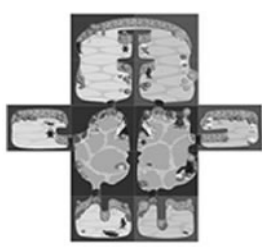

Cardiovascular System

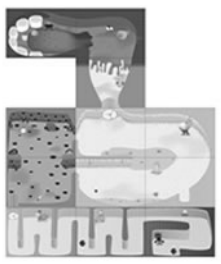

Digestive System
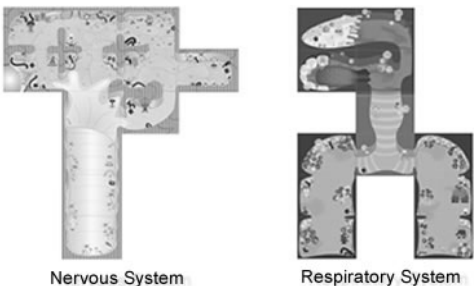

Fig. 4. Systems of the Human Body Representations in The Natomy's Journey Game

The graphic interfaces for the systems of the human body correspond to an integrated set of scenes that are coherently represented for the simulation of traveling through each of the systems. The figure 4 corresponds to the maps of each system of the human body, subdivided into 12 scenes with which the student interacts and through which he/she travels.

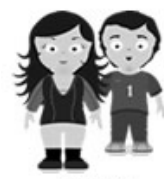

Avatars

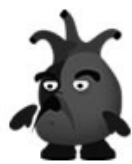

Mr. Heart

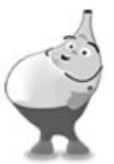

Mr. Stomach

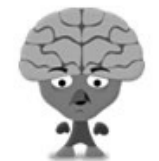

Mr. Cerebellum
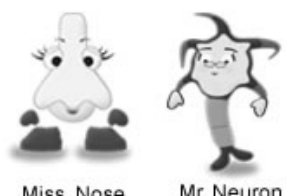

Miss. Nose Mr. Neuron

Fig. 5. Some Avatars and Characters in The Natomy's Journey Game

Avatars and Characters. Each student can pick from a total of 8 characters. The characters designed correspond mainly to organs of the human body, made into caricatures so that the students interact with them naturally and in the context of the system in which they are playing. Figure 5 shows some characters in the biological systems.

Main Interfaces. The game begins with an animated introduction according to the metaphor defined, which explains to the student the tasks that he/she has to undertake in the video game. Then there is an interface that corresponds to the main menu, 
where the user can select the kind of play (stand alone or group work), the group with which he/she will play in the game and the avatar, which will be the character that will represent him/her in the video game (see Figure 6a). After this, the student begins to play and can travel through the systems where he/she will be able to meet up with the other members of his/her group (see Figure $6 b$ ).

(a)

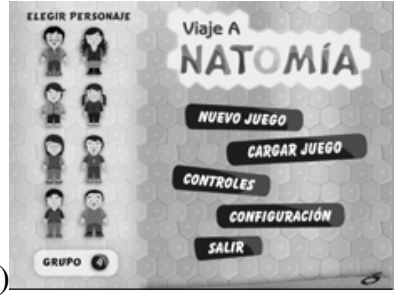

(b)

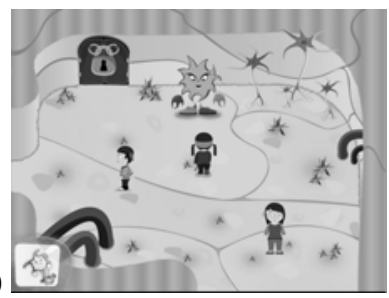

Fig. 6. Visual Interfaces of the The Natomy's Journey Game

\subsection{Model for the Virtual Environment}

The navigation through different virtual environments and spaces replicates a successful model used for commercial videogames which follow a third-person metaphor with a camera view fixed from an above and behind position. This model of navigation has been adjusted to the needs of blind children, having added auditory cues of spatial sound which allows them to form a mental construction of the space.

The representation of the surroundings is described in a XML file in which all the attributes that characterize the different scenes can be found. The XML structure contains a series of elements that define the storylines, which can also be modified, extended or eliminated.

\section{Evaluation}

\subsection{The Sample}

To evaluate the impact of the use of The Natomy's Journey Game, a study was made with sixth and seventh-grade blind and sighted children between the ages of 11 and 14 years old. Tests were applied in seven mainstream public schools in Santiago de Chile during 4 months, with the participation of 15 teachers and 326 learners. Eight legally blind learners participated in this study ( 2 with partial vision and 6 totally blind).

\subsection{Evaluation Instruments}

End-user questionnaire: This instrument was applied to evaluate the interface of The Natomy's Journey Game through 4 dimensions: game satisfaction, control and use, images and sounds quality [21]. This questionnaire consisted of 18 sentences for which the users must define to what degree each of them was fulfilled, on a scale from A Little to A Lot, with quantitative values from 1 (a little) to 10 (a lot). Some of the sentences were: "I like the videogame", "The videogame makes me active", "I felt 
I could control the videogame's situations", "The videogame is interactive", "The videogame allowed me to understand new things", "I like the sounds in the videogame", "The sounds in the videogame are clearly identifiable", and "The sounds in the videogame provide me with information"

Written guideline for the evaluation of school integration: To evaluate the level of integration, a written guideline was applied in which each participating student had to answer with opinions regarding the following four dimensions:

- Autonomy refers to the help that the students received to carry out the activities, such as tasks or movements (on a scale of 1 to 5, the higher the score, the higher the autonomy).

- Teaching/learning style refers to how the students perceived their learning style in relation to the way in which classes are held in the school (scale of 1 to 5, the higher the score the lower the agreement with the teaching style).

- Belonging to the school refers to the sense of belonging that the students had regarding their school; this asked if they felt integrated and if they identified with their class and school (on a scale of 1 to 5, the higher the score the higher the sense of belonging).

- School Integration refers to the opinion that they had on discriminatory practices or practices of school integration (on a scale of 1 to 5 , the higher the score, the higher their disagreement with discrimination).

\subsection{Procedure}

The entire intervention lasted for 4 months in each school. This period was divided into 24 work sessions: 12 of group work with the software in the computer lab in each school, and 12 of group work in the classroom using material designed specifically for the study (board games, models and activities involving the building of objects having to do with the concepts of the human body).

All throughout the execution of the study we also performed constant monitoring of the participating schools, which implied visits to the classrooms and computer labs, as well as communicating the activities through telephone and email. By the end of the fourth month of intervention and after the last gaming session, the students answered the end-user questionnaire.

Among the methods for evaluating the results, a series of both qualitative and quantitative applications were used, collecting data from the actors involved in the development of the study, teachers and the participating students. In the case of the students, quantitative instruments were applied at the beginning and the end of the study, in order to obtain opinions on the development of the stuffy and to prove that the users accepted the video game, and that it motivated them to use these virtual tools.

\subsection{Results}

Usability Results: The results obtained from the application of the end user usability test could be grouped into 4 dimensions: Game satisfaction, control and use of the videogame, sound quality, and image and color quality. 

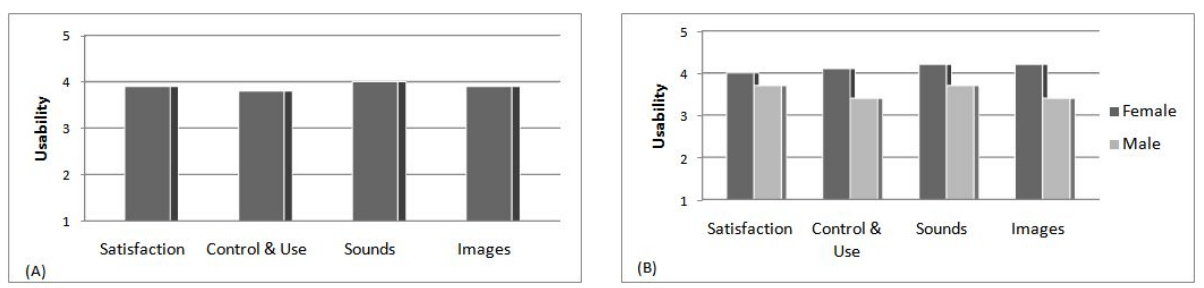

Fig. 7. (a) Usability Results by Dimension. (b) Usability Results by Gender.

As can be seen in the figure $7 \mathrm{a}$, the means obtained in each of the dimensions were high and showed that there were no big differences between the learners' valuations of the different areas analyzed regarding the usability of the software, as all the answers were located in the "agree" category.

Although there were no big differences, it could be observed that the area with the highest score was that related to the quality of the game's sounds (mean of 4 points out of a maximum of 5), which were agreeable and identifiable for the users. This ends up being very important considering that the game was designed so that learners with visual disabilities could participate. The game's images and the satisfaction with the game came in a close second, having obtained 3.9 points, which indicated that the design of the images helped to transmit information to the user and that the students liked the software in general, had fun with it, were challenged by it, believed that they learned from it and that it was able to capture their attention. The evaluation of the control and use of the game was similar (3.8 points), based on the fact that the users felt in control of the game, that they could perform different actions or stop performing actions whenever they wanted to, and on their perception that the game was interactive and easy to play, easy to use, motivating and with an interface that allowed the users to do anything simply and quickly.

It is important to point out the differentiation between the results obtained for the men and the women (figure $7 \mathrm{~b}$ ), as statistically significant differences were found in 3 of the 4 dimensions. In all 4 dimensions the women presented higher means than the men, and it was in the areas concerning use and control of the game $(\mathrm{t}=3.905$; $\mathrm{p}<0.05)$, sound quality $(\mathrm{t}=4.202 ; \mathrm{p}<0.05)$ and image quality $(\mathrm{t}=2.322 ; \mathrm{p}<0.05)$ that the differences were statistically significant. As for the dimension having to do with "game satisfaction", although the women presented a higher mean score than the men, this difference was not significant $(\mathrm{t}=1.915 ; \mathrm{p}>0.05)$.

To better understand the result of the usability evaluation is necessary to do a context analysis where the game was used. As a collaborative game, learners played in a group of 4 students and synchronically, sometimes saturating the audio between the four games. In general, the game contained heavy load of speech audio; audio that could be boring for the sighted gamers. Although there were high quality graphics in The Natomy's Journey Game including significant details, color and animation, they were not 3D graphics as learners are used today. Being primarily oriented to legally blind learners, the interaction relied strongly on keyboard, leaving aside devices such as mouse, joystick or gamepad.

School Integration Results: Regarding the items that referred to the students' autonomy in carrying out their activities, we focused on the students with visual 
disabilities. As shown in the figure 8a, there was an increase in the score between the pretest and the posttest for each one of the items. For the statement indicating that the students carried out most of their activities without assistance, there was an increase of 1.1 points between the pretest and the posttest (pretest $=2.2$ points; posttest $=3.3$ points). For the item indicating that the students tried to carry out their activities without help, there was an increase of 0.9 points (pretest $=2.9$ points; posttest $=3.8$ points); and for the item on whether or not the student studied with help from his/her parents or another person, there was an increase of 0.2 points (pretest $=4.2$ points; posttest $=4.4$ points).

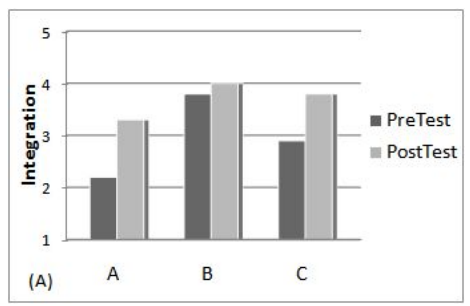

A. I carry out most of my activities without the help of my parents or another person.

B. I study with the help of my parents or another person.

C. I try to carry out my activities without help.

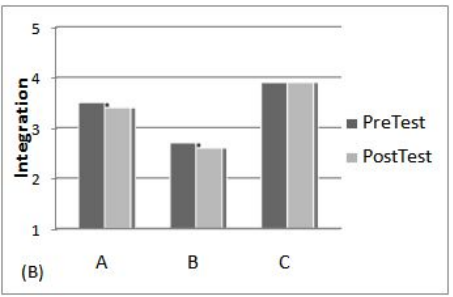

A. I feel that my way of learning is different from that of my classmates.

B. My way of learning has nothing to do with the classes taught by the teachers.

C. I wish the classes were different

Fig. 8. Integration Results. (a) Autonomy. (b) Learning Style.

As for the proximity between the classes and the students' learning styles, the figure $8 \mathrm{~b}$ shows the means obtained from the students before and after having participated in the study, demonstrating very similar means. Only for the item that indicated that the students felt that their way of learning was different from their classmates was there a decrease pretest-posttest of 0.2 points (pretest $=3.6$ points; posttest $=3.4$ points) with a significant difference $(\mathrm{t}=2.431 ; \mathrm{p}<0.05 ; \mathrm{df}=546)$. This showed that after the study the blind students considered their way of learning to be closer to those of their sighted classmates than when they first began to use the video game.

Regarding the sense of belonging that the students had with their class and their school, there were no major differences in the opinions provided before and after the study (see Figure 9). For the item indicating that they felt identified with the majority of their classmates, a higher mean was obtained (a difference of 0.4 points between the pretest and the posttest, pretest $=2.2$ points; posttest $=2.6$ points), which was also statistically significant $(\mathrm{t}=-2.374 ; \mathrm{p}<0.05 ; \mathrm{df}=538)$. This is to say that by the end of the study the students' experienced a higher degree of identification with their class, even though this was one of the lowest scoring items. The other items in which there was a pretest - posttest gain were: "I don't feel that my classmates bother me" $(0.1$ points difference, pretest $=3.1$ points; posttest $=3.2$ points; $\mathrm{t}=-0.077 ; \mathrm{p}<0.05 ; \mathrm{df}=539$ ) 
and "I feel a part of my class" $(0.2$ points difference, pretest $=3.7$ points; posttest $=3.9$ points; $\mathrm{t}=-1.610 ; \mathrm{p}<0.05 ; \mathrm{df}=536)$. The items that had no variation were: "I identify with my group of classmates" (mean of 3.5 points in both tests, $\mathrm{t}=2.793$; $\mathrm{p}<0.05$; $\mathrm{df}=$ 538 ) and "I like my classmates" (mean of 3.1 points in both tests, $\mathrm{t}=0.022 ; \mathrm{p}<0.05$; $\mathrm{df}=538$ ).

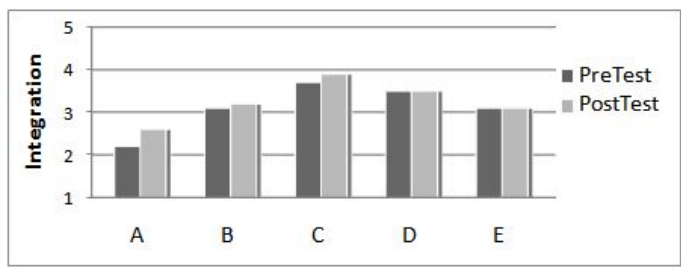

Fig. 9. Integration Results. Sense of belonging to their school.

\author{
A. I feel like I identify with most of my \\ classmates. \\ B. I don't feel that my classmates bother \\ me. \\ C. I feel a part of my class. \\ D. I identify with my group of \\ classmates. \\ E. I like my classmates.
}

The scores obtained for the opinions provided on the students' perspectives on school integration or discriminatory practices did not present any pretest - posttest gains (see Figure 10). It is important to point out that the students' opinions, both before and after the intervention, had means higher than 4.4 points, which indicated their rejection of discriminatory practices and their approval of the idea that all students have the right to an education and that everyone is different.

As for the opinions provided by the participating teachers regarding school integration, measurements were taken both at the beginning of the study and at the end, to be able to compare the possible changes that took place. One important situation that was observed is that there was an increase in the percentage of teachers that stated having had experience with school integration, from $60 \%$ at the beginning to $72.7 \%$ at the end, so considering this experience with The Natomy's Journey Game as school integration with technology.

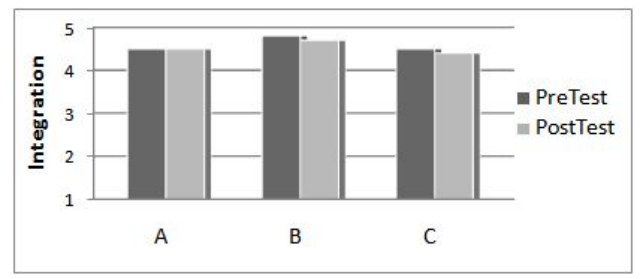

A. Discrimination is a bad thing.

B. All of us students have a right to education.

C. All of us students are different.

Fig. 10. Integration Results. School Integration.

In asking the teachers if they had implemented some strategy in the past three months for the integration of a student with visual disability, we also found that there was an increase in the final measurement, in that while initially $77.8 \%$ of the teachers had indicated "yes", at the end of the study $90.9 \%$ responded with a "yes".

Finally, in asking the teachers about how they felt working in the classroom with visually disabled students, an increase in those teachers that indicated feeling self-assured 
was observed, going from $50 \%$ for the initial measurement to $63.7 \%$ in the final measurement.

It is important to mention that the integration of learners with visual disabilities with the classroom and school classmates requires extended and sustained amount of work time that must be transversal at all school activities. Even though this fact it was possible to observe some advances as some participating teachers mentioned: "I felt that in some moments he (the blind child) became part of something", "I saw him for the first time integrated to a team work... and the group accepted him for sharing purposes", "I saw him integrated and a little more respected by their classmates because he tend to establish a negative relation with his classmates, in a defensive mode, but at the end of this experience his classmates accepted him well". All this assertions evidence qualitative relevant changes for the learner's integration considering that at the beginning it was observed that students were mostly excluded from their class, ending up as a result of participating in this study, with a more egalitarian participation in the project.

\section{Conclusions}

As a result of this study a video game for science learning by middle school blind and sighted learners was constructed and evaluated, to judge whether blind learners can interact and become socially integrated through the use of problem-solving skills and the application of specific science content.

The results of this study provide initial data and evidence that the use of video games such as The Natomy's Journey Game can improve the process for the school integration of learners with visual disabilities.

During the implementation process we made a non-participant observation to collect information about how learners and teachers appropriated and learned the methodology used. From these observations we could detect similar behaviors between learners during video gaming, as far as understanding controls and discovering new paths and goals. The participation of blind learners in particular was active and with high motivation.

The Natomy's Journey Game proposes a new way to learn science, especially the systems of the human body. The main achievement after using this game is that learners take an active role, learning in an interactive and motivated way. The learners enjoyed this new way of learning, felt motivated and participated actively and collaboratively in the tasks they had to undertake in the game.

In terms of school integration, this game helps to create a work environment in which differences are forgotten and children interact freely. They share ideas on how to solve the proposed problem as well as content knowledge among all four members of each team.

The Natomy's Journey Game allows blind children to become more socially integrated with their sighted classmates, to participate actively in society, and to be interested in the active learning of contents and new pedagogical ways of learning such as digital mobile gaming. Based on the children's comments, we point to the fact that the game allowed legally blind children to work together with their sighted peers, feeling part of the group, and this is very important issue in order to achieve a better and more complete education not only in terms of learning contents, but of school integration and teamwork skills as well. 
Acknowledgments. This report was funded by the Chilean Ministry of Education, Innovation Program, Project "Digital Inclusion for the Science Learning" and Project CIE-05 Program Center Education PBCT-CONICYT.

\section{References}

1. Adimark, VTR, \& EducarChile. Indice de generación digital 2006 (2006), http: //www.educarchile.cl/UserFiles/P0001/File/ IGD $202006 \% 20$ seminario

(Last Accessed July, 2007)

2. Balanskat, A., Blamire, R., Kefala, S.: A Review of Studies of ICT Impact on Schools in Europe. Europan SchoolNet (December 2006)

3. Cavazos, J.: Computer games. Crossroads 3(2) (Winter 1996)

4. Ellis, J.: Computer games and aggressive behavior: A review of the literature. Educational Technology 30(2), 37-40 (1990)

5. Everingham, M., Thomas, B., Troscianko, T., Easty, D.: Neural-network virtual reality mobility aid for the severely visually impaired. In: Proceedings of 2nd European Conference on Disability, Virtual Reality and Associated Technologies, pp. 183-192 (1998)

6. Facer, K., Joiner, R., Stanton, D., Reid, J., Hull, R., Kirk, D.: Savannah: mobile gaming and learning? Journal of Computer Assisted Learning 20, 399-409 (2004)

7. Feyerer, E.: Computer and Inclusive Education. In: Miesenberger, K., Klaus, J., Zagler, W.L. (eds.) ICCHP 2002. LNCS, vol. 2398, pp. 64-67. Springer, Heidelberg (2002)

8. Feyerer, E., Miesenberger, K., Wohlhart, D.: ICT and Assistive Technology in Teachers Education and Training. In: Miesenberger, K., Klaus, J., Zagler, W.L. (eds.) ICCHP 2002. LNCS, vol. 2398, pp. 297-334. Springer, Heidelberg (2002)

9. Hand, B., Alvermann, D., Gee, J., Guzzetti, B., Norris, S., Phillips, L., Prain, V., Yore, L.: Message from the "Island Group": What is literacy in science literacy? Journal of Research in Science Teaching 40(7), 607-615 (2003)

10. DeSimone, J.R., Parmar, R.S.: Middle School Mathematics Teachers' Beliefs About Inclusion of Students with Learning Disabilities. Learning Disabilities Research \& Practice 21(2), 98-110 (2006)

11. Kalyanpur, M., Kirmani, M.: Diversity and Technology: Classroom Implications of the Digital Divide. Journal of Special Education Technology 20(4), 9-18 (Fall 2005)

12. Kirriemuir, J., McFarlane, A.E.: Use of Computer and Video Games in the Classroom. Presentation to DiGRA, Utrecht (2003b)

13. Kulyukin, V., Gharpure, C., Nicholson, J., Pavithran, S.: RFID in robot-assisted indoor navigation for the visually impaired. In: Kulyukin, V., Gharpure, C., Nicholson, J., Pavithran, S. (eds.) IEEE/RSJ Intelligent Robots and Systems (IROS 2004) Conference, September - October 2004, pp. 1979-1984. Sendai Kyodo Printing, Sendai (2004)

14. Kumar, D., Ramasamy, R., Stefanich, G.: Science instruction for students with visual impairments. In: ERIC 464805, pp. 1-2 (2001)

15. Mayo, M.: Games for Science and Engineering Education. Communications of the ACM 30(35), 30-35 (2007)

16. Polya, G.: How to Sove It, A new Aspect of Mathematical Method. Princeton University Press, New Jersey (1973)

17. Prensky, M.: Digital game-based learning. Computers in Entertainment 1(1), 21 (2003)

18. Rideout, V., Roberts, D., Foehr, U.: Generation m: Media in the lives of 8-18 year-olds, pp. 8-18. Henry Kayser Family Foundation, Menlo Park (2005) 
19. Roper, R.: Using technology to teach students with mild disabilities: current trends and future technologies. Law and Disorder, Undergraduate Journal in Special Education Law (1), 54-58 (2006)

20. Sahyun, S., Gardner, S., Gardner, C.: Audio and Haptic Access to Math and Science Audio graphs, Triangle, the MathPlus Toolbox, and the Tiger printer. In: Proceedings of the 15th IFIP World Computer Congress, Vienna, September 1998, pp. 78-86 (1998)

21. Sánchez, J.: End-user and facilitator questionnaire for Software Usability. In: Usability evaluation test, Santiago, University of Chile (2003)

22. Sánchez, J.: Mobile Science Learning and Inclusion for Blind People. In: 13th Annual CyberTherapy Conference, San Diego, CA, June 23-25 (2008)

23. Sánchez, J., Sáenz, M.: Developing Mathematics Skills through Audio Interfaces. In: Proceedings of $11^{\text {th }}$ International Conference on Human-Computer Interaction, HCI 2005, Las Vegas, Nevada, USA, July 22-27 (2005) (to be published)

24. Sánchez, J., Sáenz, M.: Usability of Audio-Based Virtual Environments for Users with Visual Disabilities. In: Virtual Reality and Human Behavior Symposium, LAVAL Virtual 2007, Laval, France, April 18-22 (2007)

25. Sánchez, J., Salinas, A.: Science Problem Solving Learning through Mobile Gaming. In: MindTrek 2008 Conference, Tampere, Finland, October 8-9, pp. 49-53 (2008)

26. Schneider, J., Strothotte, T.: Constructive Exploration of Spatial Information by Blind Users. In: Proceedings of ACM ASSETS 2000, Arlington, Virginia, November 13-15, pp. 188-192 (2000)

27. Sjostrom, C.: Using haptics in computer interfaces for blind people. In: Sjostrom, C. (ed.) Proceeding of the ACM CHI 2001, Seattle, Washington, USA, March 31 - April 5, pp. 245-246 (2001)

28. Sloan, D., Phipps, L.: Helping to avoid e-discrimination in UK tertiary education. In: Proceedings of the 2003 conference on Universal usability, Vancouver, British Columbia, Canada, pp. 150-151 (2003)

29. Squire, K.: Video Games In Education. International Journal of Intelligent Simulations and Gaming 2(1), 49-62 (2003)

30. Squire, K.: Video games in education. International Journal of Intelligent Simulations and Gaming 2(1), 49-62 (2003)

31. Steinkuehler, C.: Learning in massively multiplayer online games. In: Kafai, Y.B., Sandoval, W.A., Enyedy, N., Nixon, A.S., Herrera, F. (eds.) Proceedings of the 6th International Conference of the Learning Sciences, pp. 521-528. Erlbaum, Mahwah (2004)

32. El Mercurio Newspaper (Chile), Edition of Sunday, Section C (June 15, 2008)

33. Westin, T.: Game accessibility case study: Terraformers - a real-time 3D graphic game. In: Proceedings of the 5th International Conference on Disability, Virtual Reality and Associated Technologies, ICDVRAT 2004, Oxford, UK, pp. 95-100 (2004)

34. Eriksson, Y., Gärdenfors, D.: Computer games for children with visual impairments. In: Proceedings of the 5th International conference on Disability, Virtual Reality and Associated Technologies, New College, Oxford, UK, September 20-22, pp. 79-86 (2004)

35. Archambault, D., Olivier, D.: How to make games for visually impaired children. In: Proceedings of the 2005 ACM SIGCHI international Conference on Advances in Computer Entertainment Technology. ACE 2005, June 15 - 17, vol. 265, pp. 450-453. ACM, New York (2005)

36. Grammenos, D., Savidis, A., Georgalis, Y., Stephanidis, C.: Access Invaders: Developing a Universally Accessible Action Game. In: Miesenberger, K., et al. (eds.) ICCHP 2006. LNCS, vol. 4061, pp. 388-395. Springer, Heidelberg (2006) 